\title{
Ética e cultura dialogal: transitividade crítico-reflexiva em educação
}

Ethics and culture dialogic: transit critical-reflective in education

\author{
Marcos Alexandre Alves* \\ Centro Universitário Franciscano \\ Gomercindo Ghiggi** \\ Universidade Federal de Pelotas
}

Resumo $\mathrm{O}$ artigo mostra que não há educação eticamente isenta e ideologicamente neutra. No processo de formação de um indivíduo, tornase impossível dissociar a questão educacional de um conjunto de atributos éticos. Examinando a temática da (co)relação entre ética e educação, a fim de se discutir a natureza e a função do ato educativo, $o$ artigo tem em vista as implicações e os resultados na formação do indivíduo. Também, defende que cabe ao educador a função de desenvolver, no educando, a dimensão crítico-reflexiva, explorar temas de motivação e proximidade com as reais condições vivenciais e existenciais do educando, instigar a mentalidade da pesquisa e da busca autônoma do saber, demonstrar as causas e as razões da opressão, motivar o diálogo e ouvir o que o educando tem a dizer e assumir eticamente sua responsabilidade para com a cidadania esclarecida.

PALAVRAS-ChaVE: Ética, Educação, Responsabilidade, Liberdade, Diálogo.

Abstract This paper shows that there is not ethically neutral education. In the process of forming an individual it becomes impossible to separate the issue of education from a set of ethical attributes. This paper examines the issue of (co) relation between ethics and education, in order to discuss the nature and function of the educational act, considering the implications and results in the formation of the individual. It argues that it is up to the educator to develop critical-reflexive dimension, exploring themes of motivation and proximity to the real conditions of existential and experiential learners, prompt the mentality of the research and the pursuit of knowledge autonomously, demonstrate the causes and reasons of oppression, motivate dialogue and hear what the students have to say and take their ethical responsibility to citizenship clarified.

KEYWORDS: Ethics, Education, Responsibility, Freedom, Dialogue. 


\section{Introdução}

Inicialmente, partimos de uma constatação: não há educação eticamente isenta, assim como não há educação ideologicamente neutra. Isto se constata concretamente, na educação, a partir das tomadas de decisão quanto a conteúdos programáticos, métodos de ensino/aprendizagem, dinâmicas pedagógicas, políticas públicas educacionais, sistemas de avaliação, critérios de elevação da qualidade de ensino, diretrizes curriculares nacionais, exigências mínimas de habilidades e competências por área de conhecimento, passam sempre por fortes juízos de valor, e sempre se fazem visando a algum ganho ou perda para a construção do conhecimento. Por exemplo, a opção por um ensino profissionalizante, traduz uma ideologia voltada para os pressupostos de ação do/no mercado, enquanto uma opção por ensino formativo e crítico-reflexivo traduz-se em educação libertadora, na medida em que suas preocupações colocam o educando em sintonia com o processo de desconstrução de sua condição de oprimido.

Desta premissa, pretendemos, neste texto, defender como conclusão primeira: que a questão ética, (valor, comportamento, intenção, consciência, ação humana, inter-relação social) e a questão educacional (formação, construção/aquisição de conhecimento, aperfeiçoamento cultural e científico, discernimento e preparo social) - caminham lado a lado. Esse parece ser um compromisso inelutável da própria natureza do ato educacional, da própria essência de qualquer pensamento sobre a questão e, também, algo presente em toda política pública para o setor.

Ora, torna-se imprescindível, em um contexto secular, trazer a tona a temática da (co)relação entre ética, política e educação, a fim de se discutir a natureza e função do ato educativo, tendo em vista as implicações e os resultados do processo pedagógico de formação ético-social do indivíduo. Se o processo educativo envolve construção, reconstrução ou desconstrução de conhecimentos, então se deve aceitar que sua própria ética vem condicionada por valores inscritos no processo de ensino/ aprendizagem.

Neste sentido, intencionamos mostrar que, ao final do processo de formação de um indivíduo, torna-se impossível dissociar a questão educacional do conjunto de atributos éticos que reúne. Isso não significa retornar a espinhosa controvérsia de saber se a ética é inata ou pode ser ensinada, mas significa verificar o quanto, a partir da liberdade de escolha, se pode oferecer ao indivíduo e à sociedade por meio da educação.

Entre outras coisas, se educação é o aperfeiçoamento das faculdades intelectuais, físicas e morais, é certo que tem a ver com a capacidade e o desenvolvimento de potencialidades humanas e, portanto, com a questão ética, uma vez que ela lida com as habilidades individuais de agir para si e para os outros. Ou seja, se a educação visa a formação do espírito, formar significa dar a este as condições para trabalhar, pensar, criticar, ensinar, aprender, comportar-se, avaliar. Já, a falta ou a deficiência de formação significa, por outro lado, a falta de capacitação individual e social.

Nessa perspectiva, a educação é o processo de formação não só intelectual, mas ética e política dos indivíduos. A partir da construção do conhecimento, enquanto horizonte de projeções infinita e inexaurível, a consciência abre múltiplas possibilidades de escolha, em que se descortinam múltiplas opções filosóficas, sociais, 
profissionais, culturais, políticas e existenciais. Com isto, queremos dizer, na esteira do pensamento de Paulo Freire, que é a abundância de informações, qualitativamente trabalhadas e administradas, que geram a liberdade de escolha. Ao revés, a escassez de informações associada ao processo de sua má gestão, engendram a falta de consciência crítica e, por consequência, a fácil manipulação do indivíduo. Portanto, a ignorância (como a falta de conhecimento) está na base de muitos problemas e equívocos sócio -individuais.

Em virtude disto é que educar significa crescer. Cresce no desenvolvimento e constituição de sua própria subjetividade e no compromisso social. O conhecimento que se expande se reverte em maiores chances de novas criações e novos encontros de idéias, das quais se engendram, ainda, novas alternativas de ser e de se comportar. Aí está a chave para a abertura, para a modificação e para o reforço e ênfase da ética na educação. A falta de formação é, antes de tudo, privação de escolha e castração de acertada deliberação.

Neste cenário, o papel da educação não pode ser outro, senão o de oferecer uma alternativa de ruptura com a crise ético-institucional que assola os modos de comportamento intersubjetivo e os modos de constituição das organizações e instituições sociais. Porém, de que educação se está a pensar e falar? Em que moldes se pensa ser a educação capaz desse exercício pretensamente libertário e até mesmo superior a sua vocação, normalmente compreendida como um exercício dentro da sala de adestramento de certas faculdades humanas? Até que ponto a educação tem funcionado de modo a cumprir sua importantíssima função até o presente momento? E por que, à educação, tem de ser destinada tamanha tarefa, que não seria propriamente uma missão simplesmente político-governamental?

O presente estudo fundamenta-se, especificamente, nas obras: Educação como prática de Liberdade (2002a) e Pedagogia da Autonomia (1996) de Paulo Freire. Contudo, quando necessário, faremos alusão e referência a algumas outras obras do autor, que tratam, também, da relação entre ética, política e educação, bem como de alguns comentadores que estudam esta temática. Nosso empreendimento consiste em uma abordagem bibliográfica, filosófico-histórico-social e, sobretudo, pedagógicoconceitual.

\section{A educação como prática de liberdade}

Diante destes questionamentos, torna-se necessário, para que se possa respondê-los com a devida responsabilidade e cautela, compreender as suas respectivas dimensões. E uma das chaves de compreensão das múltiplas dimensões, concernente às inquietações elencadas acima, em nosso juízo, encontram-se na seguinte pressuposição apresentada por Paulo Freire "é fundamental, contudo, partirmos do fato de que o homem é um ser de relações e não só de contatos, não apenas no mundo mas com o mundo. Estar com o mundo resulta de sua abertura à realidade, que o faz ser o ente de relações que é" (2002a, p. 47).

Com base na pressuposição que funda esse raciocínio, também se pode dizer que nada está dado e que tudo está por ser feito. Ou ainda, a de que o ser humano é um ser que está em permanente processo de construção, de invenção e reinvenção dos modos pelos quais organiza o meio em que vive, administra os conflitos a ele ineren- 
tes e constrói (inter)relações. Em outras palavras, o ser humano como ser de relação, encontra-se permanentemente nas relações, de modo que, por meio delas, se constitui a si mesmo, em contextos, em momentos, dentro do sistema ideológico, dentro de condicionantes morais, segundo tradições e costumes, dentro de linhas de educação, a partir de concepções familiares e grupais, dentro de propostas e projetos de futuro e projeções axiológicas, enfim, historicamente como um ser concreto. Nisto, não há acomodação, há processo contínuo de mutação, transmutação, valorização e revalorização, assim como de transvaloração.

Partindo-se da pressuposição de Paulo Freire, acima elencada, facilmente se compreenderá que a educação (STRECK, 2010, p. 133) não é reprodução dos saberes ou, muito menos, o espaço - físico e temporal - destinado à preparação de seres humanos para a sociedade e seus cânones, e sim o laboratório de experiências, no qual se potencializam e se amplificam os processos de mutação da sociedade, na lógica de uma experiência compartilhada entre docentes e discentes, visando à inconformidade do homem contra os paradigmas que aterrorizam e atemorizam sua libertação (STRECK, 2010, p. 243). A educação, portanto, deixa de ter um sentido "apaziguador", um sentido "doutrinador" ou "domesticador". O papel da educação é libertário e não negador, castrante, coisificador, limitador, constritor, amordaçador, ritualizador e, finalmente, abortivo.

Quem vive sob esse modelo de educação não "recebe educação", verdadeiramente, "padece educação". A massificação que castra, anula, empobrece e iguala o desigual cultural, e criativamente falando, em verdade, comete o mais terrível dos erros: "quando julga que se salva seguindo as prescrições, afoga-se no anonimato nivelador da massificação, sem esperança e sem fé, domesticado e acomodado: já não é sujeito. Rebaixa-se a puro objeto. Coisifica-se”(FREIRE, 2002a, p. 51-52). A educação, na leitura que aqui se faz, só serve enquanto é capaz de ser produtiva, ou seja, é capaz de fazer sentido na construção da cidadania (STRECK, 2010, p. 67).

A essência do ser humano, enquanto cultural, reside em seu potencial transformador. Negar isto é como negar a própria compreensão da realidade social. Caso compreenda-se que a educação é parte do processo cultural pelo qual os seres humanos se fazem e se ajustam ao que fazem, então, a educação é parte do processo produtor da cultura (STRECK, 2010, p. 98). Na esteira do pensamento de Freire, não há como negar esta outra importante pressuposição desse raciocínio: "o ser humano vai dominando a realidade. Vai humanizando-a. Vai acrescentando a ela algo de que ele mesmo é o fazedor. Vai temporalizando os espaços geográficos. Faz cultura" (FREIRE, 2002a, p. 51).

Assumidamente, apresentar essas questões e propor-se a pensá-las é algo desafiador. Mais que puramente instigante, esbarra o desatino, o inconseqüente, o transgressivo, o subversivo. No entanto, é exatamente essa sensação de "subversividade" que permite dizer que se está nascendo intelectualmente, tocando e desafiando esses temas de discussão. Isso é o que permite dizer que está se tornando sujeito do processo de construção dos valores, e não mero objeto tomado pelas coisas e instituições tal qual se faz, normalmente, aceitar pelos indivíduos que são consumidos pelos padrões sociais. Deve-se estar atento para a autofagia "que a sociedade produz, ao mesclar-se com o indivíduo e fazer dele seu objeto" (FREIRE, 2002a, p. 62). 
Desse modo, para que se atinja a ideia da educação como liberdade (STRECK, 2010, p. 241), ou seja, uma formação crítica-reflexiva, faz-se necessário abandonar a sonolência da consciência de sujeito histórico, deixar a letargia do estado de aceitação passiva dos cânones sociais, para que então se possa pensar as graves questões que estão implicadas atrás do papel da educação, como a questão do desenraizamento cultural de um povo de suas próprias matrizes, em sua função revolucionária e libertadora, sobretudo no momento atual.

\section{Cultura dialogal: transitividade crítica-reflexiva em educação}

A cultura, que deve ser fomentada pela educação realmente engajada com suas metas, consciente de sua missão e de sua tarefa, está sintonizada com o processo de fortalecimento da identidade dialogal dos indivíduos engajados em uma dimensão ético-sócio-política, ou seja, no fortalecimento de uma cultura popular (STRECK, 2010, p. 103). Numa palavra, o que se pode dizer é que a cultura dialogal que deve ser veiculada pela educação passa pela autoconsciência do povo sobre a sua realidade, e, como tal, passa por uma dimensão de compreensão dos próprios problemas, desafios e metas que se elegem para serem enfrentadas e almejadas. Ora,

A transitividade crítica, por outro lado, a que chegaríamos com uma educação dialogal e ativa, voltada para a responsabilidade social e política. Se caracteriza pela profundidade na interpretação dos problemas. Pela substituição de explicações mágicas por princípios causais. Procurar testar os "achados" e se dispor sempre a revisões. Por despir-se ao máximo de preconceitos na análise dos problemas e, na sua apreensão, esforçar-se por evitar deformações. Por negar a transferência da responsabilidade. Pela recusa a posições quietistas. Por segurança na argumentação. Pela prática do diálogo e não da polêmica. Pela receptividade ao novo, não apenas porque novo e pela não-recusa ao velho, só porque velho, mas pela aceitação de ambos, enquanto válidos. Por se inclinar sempre a argüições. (FREIRE, 2002a, p. 69-70)

Para Paulo Freire, a consciência educacional, o espírito das atividades pedagógicas do educador, deve nutrir-se dessa transitividade (STRECK, 2010, p. 408), de ingenuidade a crítica, para que, assim, seja capaz de produzir criativamente a libertação das condições nas quais se encontra imerso um povo. E é dessa consciência que se entrevê ser possível emergir a consciência acerca dos destinos que um povo pretende dar a si mesmo, não, obviamente, dentro das condições impostas por um sistema manipulador. Há, nesse modelo de consciência educacional, de responsabilidade ética (STRECK, 2010, p. 166), algo mais que a mera repetição de teorias pedagógicas, ou mera transcrição de erudição pedagógica.

Por de atrás da concepção de que a educação não mora no passivismo e nem se atrela à possibilidade de adestramento cívico, residem algumas implicações que desembocam em momentos desafiadores para as práticas educacionais, normalmente disfarçadas em falsidades e armadilhas pedagógicas que, de modo conceitual e bastante abstrato, afasta o educando do real condicionamento histórico no qual se encontra de fato. Nessa perspectiva, realmente, fica muito difícil à escola cumprir qualquer papel senão aquele que determinados interesses antepuseram sobre a sua missão (FREIRE, 2002a). 
Todo este processo de desenraizamento é lento e afasta o educando dos temas complicados da agenda sócio-política. De modo que, onde imperam determinados preconceitos sociais e educacionais, em nome da preservação e não exposição dos estudantes a temas ditos "perigosos" ou "sujos", é impossível se pensar em liberdade de pensamento, em fomento à criatividade; e o que dizer de uma cultura da dialogicidade e da construtividade eticamente responsável?

$\mathrm{Na}$ prática educacional, quando isto se constata, estamos diante da mais coerente demonstração de incoerência político-educacional. É a mais inequívoca transmissão da incapacidade de gestar a cidadania do seio de suas práticas educacionais e políticas, uma vez que sua inexperiência na dimensão do político se projeta para dentro de todas as demais instituições sociais. Trata-se de pensar o quanto a sociedade não está dissociada de si mesma, na medida em que deixa, ao abandono, a possibilidade de aprender no diálogo (STRECK, 2010, p. 117) a força e o poder da resistência dialogal aos desencontros da hegemonia do mercado. Desta forma, as práticas educacionais continuam reproduzindo modelos acalentados por antigas matrizes politicamente orientadas e interessantes, que acentuam a inconsciência do povo de suas próprias necessidades.

E esse ciclo vicioso desemboca em sala de aula, nas mentalidades dos educadores e nas rodas de intelectuais e universitários. A cultura da antidialogicidade, na educação, tem tudo a ver com a cultura do paternalismo, do assistencialismo, do solidarismo que se encontram como vocação de uma política autoritária (FREIRE, 2002b). Assim, para Paulo Freire a cultura do anti-diálogo implica:

$$
\begin{aligned}
& \text { uma relação vertical de A sobre B, é o oposto a tudo isso.É desamo- } \\
& \text { roso. É acrítico e não gera criticidade, exatamente porque desamo- } \\
& \text { roso. Não é humilde. É desesperançoso. Arrogante. Auto-suficien- } \\
& \text { te. No antidiálogo quebra-se aquela relação de simpatia entre seus } \\
& \text { pólos, que caracteriza o diálogo. Por tudo isso, o antidiálogo não } \\
& \text { comunica. Faz comunicados. (FREIRE, 2002a, p. 116) }
\end{aligned}
$$

A cultura da responsabilidade social ainda não está amadurecida para a educação. Continua-se a fala em cidadania quando se fala em comemorar datas cívicas, mas não se confere instrumentos e ferramentas pelos quais o educando possa mudar um pouco seu ambiente de convívio, a quadra de sua casa, a praça de sua rua, o sistema de trabalho de sua empresa, os esquemas de distribuição e participação no poder (STRECK, 2010, p. 317). O continuísmo dos conceitos políticos tradicionais é uma realidade para educadores e educandos, pois ainda não se percebeu, senão parcamente, o profundo relacionamento que a educação mantém com as estruturas e os compromissos políticos de um povo.

O conhecimento é chave para inúmeras revoluções, tais como: éticas, tecnológicas, institucionais, filosóficas, culturais e socioeconômicas. Assim, o engajamento do povo, nos processos de produção de si mesmo, é atitude fundamental que passa pela formação que a educação possibilita, dependendo dos moldes "formadores" ou "amoldadores" que aplique sobre os educandos (FREIRE, 2002b). Neste sentido, negar a politicidade (STRECK, 2010, p. 323) do ato educacional é negar a sua essência (dialógica), o que representa a perda de sentido da própria experiência da educação. 


\section{Cidadania ativa: a co-relação entre ética, política e educação}

Para Paulo Freire, entre a ética, a política, a educação (cidadania), como entre o educador e seu ofício profissional há uma curiosa relação de comprometimento. Se a educação lida com a formação, não é por outro motivo que se pode dizer que a educação possui o diferencial de requerer a ética como condição sine qua non para sua expressão e exercício - cidadania. A educação foi feita para formar, e não para deformar. "Educar é substancialmente formar" (FREIRE, 1996, p. 37).

No pensamento de Freire, a prática educativa está imbricada a atitudes ético-responsáveis. Ou seja,

me acho absolutamente convencido da natureza ética da prática educativa enquanto prática especificamente humana. É que, por outro lado, nos achamos, no nível do mundo e não apenas no Brasil, de tal maneira submetidos ao comando da malvadez da ética do mercado, que me parece ser pouco tudo o que façamos na defesa e na prática da ética universal do ser humano. Não podemos nos assumir como sujeitos da procura, da decisão, da ruptura, da opção, como sujeitos históricos, transformadores, a não ser assumindo-nos como sujeitos éticos. Nesse sentido, a transgressão dos princípios éticos é uma possibilidade, mas não é uma virtude. Não podemos aceitá-la. (FREIRE, 1996, p. 19)

Contudo, para o autor, não basta afirmar ou discursar teoricamente sobre isso, mas torna-se imprescindível o desenvolvimento de uma pedagogia apropriada, que capaz de produzir, no educando, condições de perceber, sentir e se engajar no projeto social de sua própria formação. Se isso é importante, deve-se, então, concluir nada mais que o docente, o agente da educação, deve estar preparado para desafiar, o que pressupõe a importante tarefa de autocondicionar-se a pensar diferentemente.

Parece que prática ética, prática educativa e prática política (prática cidadã) estão saudavelmente imbricadas no ato de ensinar, e isso num sentido muito democrático, o que vale dizer, não num sentido de que as aulas devam se converter em "lavagem cerebral" do educando por ideologias políticas determinadas. Isso porque o sentido da consciência cidadã, aqui trabalhado, não é o de uma consciência político-partidária, ou muito menos o de uma consciência exclusivista, refratária e impermeável a novas demandas políticas. Ou seja, a consciência (STRECK, 2010, p. 86) reflexiva-crítica é sinônima de preocupação com o social, com as carências reais que envolvem certa comunidade e suas demandas, com o momento histórico vivido, com os projetos sociais em andamento e as grandes e pequenas questões que incomodam uma sociedade em dado contexto. Aqui, política (STRECK, 2010, p. 321) não significa clausura ou unilateralidade político-partidária, mas sim liberdade, isto é, reconexão do pessoal e do político, democracia (STRECK, 2010, p. 112). E disso não pode o educador democrático se esquivar.

Portanto, educador democrático não é somente aquele que é capaz de se tornar permeável à práticas pedagógicas permissivas, mas, sobretudo, aquele que, fazendo de sua tarefa um importante instrumento de criticidade (STRECK, 2010, p. 97), é capaz de interagir entre o senso comum, a ciência, a politicidade do saber, as 
necessidades cotidianas, despertando, em seus educandos, o interesse no saber, no conhecer e no agir. Ao contrário, educador autoritário traz consigo o estigma da docência como transmissão de informações, o educando visto como o depósito de dados e informações, a sala de aula como o grande container onde todos os dias se lançam e ruminam as velhas nuances e fórmulas de sempre.

O educador autoritário não está interessado na liberdade, mas sim na concepção, segundo a qual se lança informação, até para que a sensação de dever cumprido lhe satisfaça (GHIGGI, 2001). No lugar da aventura, brota a amargura; no lugar da leveza, nasce a aspereza; no lugar da criatividade, nasce a brutalidade; no lugar da liberdade, surge a autoridade. Assim revelado, o docente deixa de representar uma alternativa para o desvendar, e passa a ser o repressor institucional para a execução de currículos previamente impostos pela administração escolar e pelo sistema formal de ensino. Desestimulado, o docente é, também, desestimulante, exatamente porque se converteu em um burocrata do ensino, um reprodutor de conhecimentos estabelecidos; em seus olhos não há a chama da curiosidade, mas se esfria o cinza-nebuloso do desgosto oriundo das amarguras de sua profissão.

Paulo Freire define a autoridade desse docente, como "mandonista, rígida, não conta com nenhuma criatividade do educando. Não faz parte de sua forma de ser, esperar, sequer, que o educando revele o gosto de aventurar-se" (FREIRE, 1996, p. 104). Neste sentido, este educador é frustrado e, ao mesmo, tempo frustrante. Que tipo de atitude cultiva? Que tipo de sentimento desperta nos educandos? Quais suas atitudes perante a sociedade? Quais suas concepções em sala de aula? Que pensa da formação educacional? Será que carrega esses estigmas de pensar a educação de uma forma como descrita a seguir?

Suas práticas educativas se convertem, portanto, em práticas esterelizadoras da jovialidade do conhecimento, do despertar de novos olhares, da criação de diferentes consciências. Ora, para Paulo Freire, se há uma prática exemplar como negação da experiência formadora, esta é a que dificulta ou inibe a curiosidade do educando e, em consequência, a do educador. Ou seja, é que o educador, entregue "a procedimentos autoritários ou paternalistas que impedem ou dificultam o exercício da curiosidade do educando, termina por igualmente tolher sua própria curiosidade" (FREIRE, 1996, p. 94).

O educador autoritário não percebe no diálogo a possibilidade de construção de algo conjunto com o educando, pois suas concepções de mundo são verticalistas (GHIGGI, 2001). Nisso tudo há uma profunda diferença de conceito e percepção da função educativa. O não-diálogo é uma atitude simplificadora da realidade, pois torna a passividade de uma sala de aula o repasto perfeito para a não-criação, para o não-fomento; nisso mora certo medo do diferente, do novo, do inusitado, do inesperado. Educação, se é formação, pressupõe diálogo, para o que se deve estar aberto para construir por meio dele. Nesse sentido, pela via do diálogo, a educação pode significar libertação. Para isso, ela deve estimular:

A pergunta, a reflexão crítica sobre a própria pergunta, o que pretende com esta ou com aquela pergunta em lugar da passividade em face das explicações discursivas do professor, espécie de respostas e perguntas que não foram feitas. Isto não significa realmente que devamos reduzir a atividade docente em nome da defesa da curio- 
sidade necessária, a puro vaivém de perguntas e respostas, que burocraticamente se esterilizam. A dialogicidade não nega a validade de momentos explicativos, narrativos, em que o professor expõe ou fala do objeto. $O$ fundamental é que professor e alunos saibam que a postura deles, do professor e do aluno, é dialógica, aberta, curiosa, indagadora e não apassivada, enquanto fala ou enquanto ouve. $\mathrm{O}$ que importa é que o professor e os alunos se assumam epistemologicamente curiosos. (FREIRE, 1996, p. 95-96)

A verdadeira função da educação reside e evidencia-se como prática de liberdade (FREIRE, 2002a). Neste sentido, a educação comprometida eticamente não pode se deixar representar pela simplicidade e comodidade das concepções bancárias pelas quais o conhecimento se faz, se transmite e se reproduz, inaugurando a inatividade, a charlatanice e a apatia de gerações inteiras. Devem mesmo ser exterminadas as tentativas de conversão ou assimilação da educação com a concepção bancária de mundo (FREIRE, 2005).

\section{Considerações finais}

Com esta investigação pudemos constatar, a partir da esteira do pensamento de Paulo Freire, que, quando se pensa na função do educador, deve-se pensar nele desempenhando uma tarefa humanista (ético-responsável), o que também significa fazer perceber ao educando que se encontra na condição de oprimido para despertá-lo em direção à libertação, por meio de práticas convenientes e adequadas para tanto. Para que isso ocorra, a humanização vai no sentido contrário de qualquer concepção bancária da educação, e verte-se no sentido criativo da educação conscientizadora, engajadora, habilitante, estimulante e produtiva.

No lugar da fixação, da reprodução, do continuísmo, surgem a revolução, a renovação, a libertação, a abertura, enfim, a criação. Será que as políticas públicas estão preparadas para tanto? Será que educadores estão prontos para esse desafiador projeto de educação? Será que as instituições educacionais estão prontas para receber e abrigar essa concepção de educação? Será, principalmente, que a pedagogia ensinada aos professores está preparada para isso? Se isso é praticado, o fruto não é outro senão a imbricação, a umbilical relação entre educador e educando.

Portanto, cabe ao educador, enquanto profissional da educação e investido da função de desenvolver no educando a dimensão crítico-reflexiva, explorar temas de motivação e proximidade com as reais condições vivenciais e existenciais do povo, instigando a mentalidade da pesquisa e da busca autônoma pelo saber, demonstrando as causas e as razões da opressão, motivando o diálogo e ouvindo o que o educando tem a dizer, assumindo eticamente sua responsabilidade profissional e social com a cidadania e a responsabilidade política, demonstrando e agindo para a vida e negando a morte abortiva das mentalidades, também permitindo que a liberdade invada os modos pelos quais as práticas pedagógicas se fazem, assumindo atitudes democráticas na condução dos trabalhos acadêmicos, tornando-se um educador-investigador para trazer sempre novos estímulos aos alunos e a si mesmo, combatendo toda forma de exclusão social que se possa instaurar dentro da escola ou da sala de aula, instaurando e assumindo a politicidade do mister educativo, formando e informando o educando quanto a sua própria realidade histórico-social, veiculada paixão pela mobilização que a educação é 
capaz de proporcionar, vivenciando por suas atitudes o compromisso assumido com a sala de aula, são algumas formas de dar passos em direção à liberdade do oprimido de sua condição, bem como em direção à formatação de uma nova conjuntura educacional capaz de motivar a superação de todos os percalços pelas suas próprias forças.

Para tanto, é necessário o fortalecimento do sistema educacional, visando à implementação e à abertura de novas diretrizes para a sociedade. E isso não ocorrerá sem uma política sistemática de valorização e capacitação do profissional da área da educação. O desenvolvimento ético-político só é possível com incentivos educacionais concretos e palpáveis. Essa é a forma de libertação de um povo de sujeições de diversas naturezas, entre elas, o colonialismo cultural. Deve-se conceder, a um povo, o acesso a sua história, a seus modos costumeiros de se organizar, permitindo-lhe a valorização de suas práticas tradicionais, a consciência de suas estruturas morais, as normas de seu éthos peculiar.

\section{Referências}

BARRETO, V. Paulo Freire para educadores. São Paulo: Arte e Ciência, 2003.

CALADO, A. J. F. (Org.). Revisitando Paulo Freire: diálogo, prática docente, corpo consciente e inspiração cristã-marxiana. João Pessoa: Idéia, 2008.

FEITOSA, S. C. S. Método Paulo Freire: a reinvenção de um legado. Brasília: Liber Livro, 2008.

FREIRE, A. M. A. (Org.). A pedagogia da libertação em Paulo Freire. São Paulo: Editora UNESP, 2001.

FREIRE, P. Educação como prática de liberdade. São Paulo: Paz e Terra, 2002a.

. Educação e atualidade brasileira. São Paulo: Cortez, 2002b.

. Pedagogia da autonomia. São Paulo: Paz e Terra, 1996.

. Pedagogia do Oprimido. São Paulo: Paz e Terra, 2005.

GADOTTI, M.; FREIRE, P.; GUIMARÃES, S. Pedagogia: diálogo e conflito. São Paulo: Cortez, 1995.

GHIGGI, G. A pedagogia da autoridade a serviço da liberdade. Pelotas: Seiva, 2001.

GHIGGI, G.; PIZZI, J. (Org.). Diálogo crítico-educativo: um debate filosófico. Pelotas: EDUCAT, 2008.

GHIGGI, G.; SILVEIRA, F. T.; PITANO, S. C. Leituras de Paulo Freire: contribuições para o debate pedagógico contemporâneo. Pelotas: Seiva, 2007.

HENZ, C. I. (Org.). Educação humanizadora e os desafios da diversidade. Santa Cruz do Sul: EDUNISC, 2009.

STRECK, D. R. (Org.). Paulo Freire: ética, utopia e educação. Petrópolis, RJ: Vozes, 1999.

STRECK, D. R.; REDIN, E.; ZITKOSKI, J. J.(Orgs.). Dicionário Paulo Freire. 2a ed. Belo Horizonte: Autêntica Editora, 2010.

ZITKOSKI, J. J. Paulo Freire \& a educação. Belo Horizonte: Autêntica, 2006. 
* Professor Doutor do Centro Universitário Franciscano, Santa Maria, Rio Grande do Sul - Brasil.

** Professor Doutor da Universidade Federal de Pelotas, Pelotas, Rio Grande do Sul - Brasil.

\section{Correspondência}

Marcos Alexandre Alves - Centro Universitário Franciscano, Área das Ciências Humanas. Rua dos Andradas, 1614, Centro, CEP: 97010-032 - Santa Maria, Rio Grande do Sul - Brasil.

E-mail: maralexalves@gmail.com - gghiggi@terra.com

Recebido em 10 de janeiro de 2013

Aprovado em 17 de abril de 2014 
